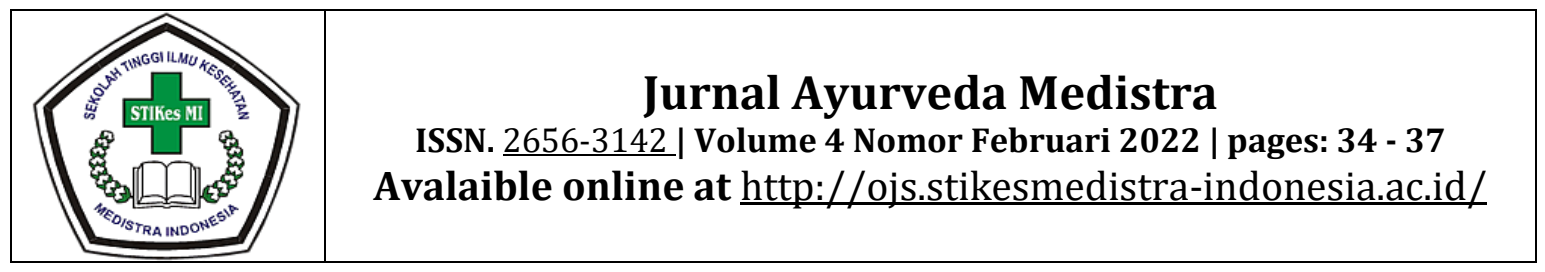

\title{
HUBUNGAN SLEEP HYGIENE DENGAN KUALITAS TIDUR MAHASISWA FAKULTAS ILMU KOMUNIKASI UNIVERSITAS BHAYANGKARA JAKARTA RAYA 2021
}

\author{
Dinda Nur Fajri Hidayati Bunga1*, Tias Tri Asyhari2, Lina Indrawati3 \\ 1 Program Studi Keperawatan (S1) STIKes Medistra Indonesia, dindanfhbunga@gmail,com, 081217889945 \\ 2Program Studi Keperawatan (S1) STIKes Medistra Indonesia, tyastriasyhari@gmail.com, 08978169098 \\ ${ }_{3}^{3}$ Program Studi Pendidikan Profesi Ners STIKes Medistra Indonesia, aisyah150416@gmail.com, \\ 081316317244
}

\begin{abstract}
Abstrak
Remaja dan dewasa muda diindetifikasi sebagai populasi yang sangat beresiko tinggi mengalami masalah tidur dan mengantuk disiang hari oleh The National Institueof health (NIH). Kelomopok mahasiswa adalah kelompok yang mempunyai aktivitas yang cukup padat. Pada pagi hari sebagian besar dari mahasiswa sudah bangun lebih awal untuk mempersiapkan kuliah. Kualitas tidur mahasiswa dapat dipengarui beberapa factor salah satunya dapat di sebabkan oleh penerapan sleep hygiene yang buruk. Sleep Hygiene terdiri dari lingkungan tidur, kebiasaan serta perilaku yang sering di lakukan sebelum tidur. Mahasiswa dapat maningkatkan kualitas tidurnya dengan baik apabila dapat melakukan kegiatan sleep hygiene dengan baik. Untuk menjelaskan hubungan antara sleep hygiene dengan kualitas tidur pada mahasiswa fakultas ilmu komunikasi Universitas Bhayangkara Jakarta raya. Metode penelitian ini adalah desain bersifat kuantitatif dengan menggunakan rancangan jenis penelitian analitik cross sectional. Populasi penelitian ini adalah Mahasiswa Aktif Fakultas Universitas Bhayangkara Jakarta Raya, dengan menggunakan tekhnik simple random sampling. Berdasarkan hasil analisa statistik menggunakan uji chi square test diperoleh nilai $p$ value sebesar $0,005 \leq 0,05$. Hal ini menunjukkan bahwa Ho ditolak. Ada Hubungan Sleep Hygiene Dengan Kualitas Tidur Mahasiswa Fakultas IImu Komunikasi Universitas Bhayangkara Jakarta Raya 2021.
\end{abstract}

Kata kunci: Sleep Hygiene, Kualitas Tidur, Mahasiswa

\section{Abstract}

Adolescents and young adults have been identified as a population at high risk of experiencing sleep problems and daytime sleepiness by The National Institute of Health (NIH). The student group is a group that has a fairly solid activity. In the morning most of the students got up early to prepare for class. The quality of student sleep can be influenced by several factors, one of which can be caused by the application of poor sleep hygiene. Sleep Hygiene consists of the sleeping environment, habits and behaviors that are often done before bed. Students can improve their sleep quality well if they can perform sleep hygiene activities properly. To explain the relationship between sleep hygiene and sleep quality in students of the Faculty of Communication Sciences, Bhayangkara University, Greater Jakarta. This research method is a quantitative design using a cross sectional analytic research design. The population of this research is active students of Bhayangkara University, Jakarta Raya University, using simple random sampling technique. Based on the results of statistical analysis using the chi square test, the $p$ value of 0.0050 .05 was obtained. This shows that $\mathrm{HO}$ is rejected. There is a Relationship between Sleep Hygiene and Sleep Quality for Students of the Faculty of Communication Sciences, Bhayangkara University, Jakarta Raya 2021.

Keywords: Sleep Hygiene, Sleep Quality, College Student

\section{PENDAHULUAN}

Remaja dan dewasa muda sudah di indetifikasi sebagai populasi yang sangat beresiko tinggi mengalami masalah tidur dan mengantuk disiang hari oleh The National Institueof health $(\mathrm{NIH})$. dewasa muda dan mahasiswa juga dilaporkan memiliki prevelensi yang cukup tinggi terhadap gangguan tidur atau kualitas tidur yang buruk. Masalah pada tidur dapat menyebabkan kelelahan, kecelakaan dan penurunan kinerja $^{3}$

Secara fisiologis, Kualitas tidur yang buruk dapat menimbulkan kesehatan fisiologis dan 
psikologis dapat menurun. Kualitas tidur yang buruk dapat menyebabkan menurunnya tingkat kesehatan sehingga mudah kelelahan atau mudah letih. Sedangkan secara psikologis, rendahnya kualitas tidur dapat menimbulkan ketidakseimbangan emosional, tidak percaya diri sehingga menimbulkan kecerobohan. Kebutuhan tidur yang cukup tidak hanya ditentukan oleh factor kualitas tidur. Kualitas tidur mencangkup aspek kuantitatif dan kualitatif tidur, seperti lamanya jam tidur, frekuaensi terbangun serta aspek subjektif seperti kepulasan tidur. ${ }^{16}$

Setiap tahun di dunia diperkirakan sekitar $20 \%-55 \%$ orang dewasa mengalami adanya gangguan kualitas tidur dan sekitar 17\% orang mengalami gangguan tidur yang cukup serius. ${ }^{16}$ Menurut penelitian yang di lakukan oleh INDEPTH WHO-SAGE pada tahun 20062007 menunjukan bahwa angka kejajian kualitas tidur di Indonesia sebesar 9,4\%. Beberapa penelitiain melaporkan bahwa kemampuan tidur pada dewasa muda adalah 80-90 \% (Di daerah Mulyorejo Surabaya pada tanggal 10 April 2012 dari 20 responden terdapat 13 mahasiswa atau sekitar 65\% mengalami kualitas tidur yang tidak baik, 5 mahasiswa atau sekitar $25 \%$ mengalami kualitas tidur yang cukup baik dan 2 mahasiswa atau $10 \%$ tidak memiliki masalah pada kualitas tidurnya. ${ }^{16}$

Kelomopok mahasiswa adalah kelompok yang mempunyai aktivitas yang cukup padat. Pada pagi hari sebagian besar dari mahasiswa sudah bangun lebih awal untuk mempersiapkan kuliah. Mahasiswa dapat merasakan kesulitan tidur akibat adanya beban tugas yang menuntut mereka untuk tidur hingga larut.

Kualitas tidur mahasiswa dapat dipengarui beberapa factor salah satunya dapat di sebabkan oleh penerapan sleep hygiene yang buruk. Sleep Hygiene terdiri dari lingkungan tidur, kebiasaan serta perilaku yang sering di lakukan sebelum tidur ${ }^{8}$. Deprivasi tidur akibat buruknya sleep hygiene juga dapat menimbulkan gangguan mood, kemampuan untuk belakar serta kemampuan untuk mengelola informasi. Berdasarkan hal tersebut mahasiswa menjadi salah satu kelompok yang beresiko terhadap praktik sleep hygiene ${ }^{6}$.

Mahasiswa Fakultas Komunikasi Universitas Bhayangkara Jakarta Raya memiliki aktivitas yang padat yaitu menjalankan aktifitas perkuliahan, menyelesaikan tugas akhir atau skripsi, berdiskusi online, serta menyelesaikan tugas tugas yang di berikan olehh Dosen. Oleh karena itu, mahasiswa FIKOM UBJ bersiko untuk mengalami masalah tidur karena terlalu focus pada kegiatan perkuliahan atau tugas, sehingga tidak ada waktu untuk melalukan sleep hygiene.

Berdasarkan Latar Belakang di atas maka peneliti tertarik untuk mengetahui apakah adanya hubungan antara Sleep Hygiene dengan Kualitas Tidur pada Mahasiswa Fakultas IImu Komunikasi Universitas Bhayangkara Jakarta Raya Bekasi 2021.

\section{METODE PENELITIAN}

Penelitian ini menggunakan observasional kuantitatif analitik. Metode penelitian yang digunakan adalah cross sectional. Populasi dalam penelitian ini adalah mahasiswa ilmu komunikasi universitas Bhayangkara Jakarta Raya Tahun 2021 berjumlah 201 mahasiswa. Penelitian ini dilakukan kepada mahasiswa ilmu komunikasi universitas Bhayangkara Jakarta Raya. Waktu penelitian pada Tanggal 29 Juli s/d 16 Agustus 2021. Analisa bivariat menjelaskan hubungan hubungan sleep hygiene dengan kualitas tidur mahasiswa fakultas ilmu komunikasi universitas bhayangkara jakarta raya 2021. Uji statistik menggunakan uji chi-suare.

\section{Metode Pengumpulan Data}

Jumlah sampel sebanyak 134 responden. Tekhnik pengambilan sampling pada penelitian ini adalah simple random sampling yaitu metode pengambilan sampel secara acak sederhana dengan asumsi bahwa karakteristik tertentu yang dimiliki oleh populasi tidak dipertimbangkan dalam penelitian. Alat pengumpulan data dalam penelitian ini menggunakan kuesioner yang terdiri dari 13 soal pertanyaan terkait Sleep Hygiene dan 15 pernyataan terkait Kualitas Tidur. Analisis yang digunakan dalam penelitian ini adalah analisa univariat untuk mengetahui distribusi frekuensi variabel yang di teliti, Sleep Hygiene dan Kualitas Tidur.

\section{HASIL DAN PEMBAHASAN}

\section{Sleep Hygiene}

Tabel 1. Distribusi frekuensi sleep hygiene pada mahasiswa fakultas ilmu komunikasi universitas bhayangkara Jakarta raya

\begin{tabular}{ccc}
\hline kategori & Frekuensi $(\boldsymbol{f})$ & Presentase (\%) \\
\hline Baik & 8 & 6.0 \\
Sedang & 98 & 73.1 \\
Buruk & 28 & 20.9 \\
\hline
\end{tabular}




\begin{tabular}{ccc}
\hline Total & 134 & 100 \\
\hline Sumber: Kuesioner
\end{tabular}

Sumber: Kuesioner Dinda, Agustus 2021

Berdasarkan tabel 1 dapat diketahui bahwa dari jumlah 134 responden paling banyak dominanpada kategori sedang yaitu berjumlah 98 responden $73.1 \%$

2. Kualitas Tidur

Tabel 2. Distribusi frekuensi kualitas tidur pada mahasiswa fakultas ilmu komunikasi universitas bhayangkara Jakarta raya

\begin{tabular}{ccc}
\hline Kategori & $\begin{array}{c}\text { Frekuensi } \\
\text { (f) }\end{array}$ & $\begin{array}{c}\text { Persentase } \\
(\%)\end{array}$ \\
\hline
\end{tabular}

\begin{tabular}{ccc}
\hline Baik & 45 & 33,6 \\
Cukup & 79 & 59 \\
Kurang & 10 & 7,5 \\
\hline Total & 134 & 100
\end{tabular}

Sumber: Kuesioner Dinda, Agustus 2021

Berdasarkan tabel 2 dapat diketahui bahwa dari 134 responden paling banyak kategori cukup berjumlah 79 responden $(59 \%)$

3. Hubungan Sleep Hygiene dengan Kualitas Tidur

Tabel 3. Hubungan Sleep Hygiene dengan Kualitas Tidur Mahasiswa Fakultas IImu Komunikasi Universitas Bhayangkara Jakarta Raya Tahun 2021

\begin{tabular}{|c|c|c|c|c|c|c|c|c|c|}
\hline & \multicolumn{9}{|c|}{ Kualitas tidur } \\
\hline & \multicolumn{2}{|c|}{ Baik } & \multicolumn{2}{|c|}{ Cukup } & \multicolumn{2}{|c|}{ Kurang } & \multicolumn{2}{|c|}{ Total } & \multirow[b]{2}{*}{$\begin{array}{c}P \\
\text { Value }\end{array}$} \\
\hline $\begin{array}{l}\text { Sleep } \\
\text { Hygiene }\end{array}$ & $\mathrm{F}$ & $\%$ & $\mathrm{~F}$ & $\%$ & $\mathrm{~F}$ & $\%$ & $\mathrm{~F}$ & $\%$ & \\
\hline Baik & 3 & 2,2 & 4 & 3,0 & 1 & 0,7 & 8 & 6,0 & \\
\hline sedang & 40 & 29,9 & 54 & 40,3 & 4 & 3,0 & 98 & 73,1 & 0005 \\
\hline buruk & 2 & 1,5 & 21 & 15,7 & 5 & 3,7 & 28 & 20,9 & 0,005 \\
\hline Total & 45 & 33,6 & 79 & 59,0 & 10 & 7,5 & 134 & 100,0 & \\
\hline
\end{tabular}

Sumber: Kuesioner Dinda, Agustus 2021

Berdasarkan Tabel 3 dapat di ketahui bahwa dari 134 responden $(100,0 \%)$ terdapat responden paling banyak yaitu pada kategori Sleep Hygiene sedang dengan Kualitas Tidur cukup yang berjumlah 54 responden $40,3 \%$.

Hal ini sejalan dengan hasil penelitian lain yang di lakukan oleh (Minar, 2019) diperoleh nilai $p$-value sebesar $0,010<(0,05)$. Yang artinya terdapat Korelasi Antara Sleep Hygiene Dengan Kualitas Tidur Pada Mahasiswa Fakultas Kedokteran Universitas Sumatera Utara Angkatan 2017. Hasil penelitian lain juga di lakukan oleh (Rahmah et al., 2018) bahwa ada Hubungan Signifikan Antara Sleep Hygiene Dengan Kualitas Tidur Pada Lansia Di Panti Wredha Harapan Ibu Ngaliyan dengan hasil nilai $p$ - value sebesar $0,000<(0,05)$.

Menurut analisa penelitian pada peneliti ini bahwa ada Hubungan Antara Sleep Hygiene Dengan Kualitas Tidur Pada Mahasiswa Fakultas IImu Komunikasi Universitas Bhayangkara Jakarta Raya Tahun 2021. Hal ini menunjukan bahwa mayoritas responden dengan sleep hygiene yang baik dapat meningkatkan kualitas tidur yang baik pula. Responden pada peneliti ini juga menunjukan bahwa sleep hygiene yang kurang baik dapat berpengaruh terhadap kualitas dan kuantitas tidur seseorang. Semakin baik sleep hygiene yang di miliki oleh responden maka semakin baik pula kualitas tidur seseorang sehingga bisa menyadari pentingnya melakukan sleep hygiene untuk meningkatkan kualitas tidur seseorang.

\section{SIMPULAN DAN SARAN}

Berdasarkan hasil penelitian dan pembahasan, maka simpulan yang diambil dari penelitian ini adalah sebagai berikut :

1. Penerapan sleep hygiene pada Mahasiswa Fakultas IImu Komunikasi Universitas Bhayangkara Jakarta Raya Tahun 2021 mayoritas dalam kategori sedang.

2. Kualitas Tidur Mahasiswa Fakultas IImu Komunikasi Universitas Bhayangkara Jakarta Raya Tahun 2021 mayoritas dalam kategori cukup.

3. Adanya Hubungan Sleep Hygiene Dengan Kualitas Tidur Mahasiswa Fakultas IImu Komunikasi Universitas Bhayangkara Jakarta Raya Tahun 2021. Responden telah mampu memahami dan mengaplikasikan proses sleep hygiene yang cukup baik dalam meningkatkan kualitas tidur yang baik. 


\section{DAFTAR PUSTAKA}

1. Anies. (2021). Waspada Susah Tidur: Seluk Beluk Gangguan Tidur Di Segala Usia. Arruzz Media.

2. Dharma, K. K. (2015). Metodologi penelitian Keperawatan (pedoman Melaksanakan dan Menerapkan hasil Penelitian). CV. Trans Info Media.

3. Hestiani Windari Br Ginting, D. G. (2003). Pendahuluan Metode Hasil. 2, 1-9.

4. Hidayat, A. A. A., \& Uliyah, M. (2016). Buku Ajar IImu Keperawatan Dasar. Salemba Medika.

5. Lee, K. Y., \& HS Lam, M. (2017). Physical Activity Measurements in Sport Field: Objective or Subjective Measures? Sports Nutrition and Therapy, 02(02), 1000122. https://doi.org/10.4172/24736449.1000122

6. Mardalifa, T., Yulistini, Y., \& Susanti, R. (2018). Hubungan Sleep Hygiene dengan Hasil Belajar Blok Pada Mahasiswa Tahap Akademik Fakultas Kedokteran. Jurnal Kesehatan Andalas, 7(4) 504.

https://doi.org/10.25077/jka.v7i4.909

7. Minar, E. T. I. O. (2019). Korelasi sleep hygiene dengan kualitas tidur pada mahasiswa fakultas kedokteran universitas sumatera utara angkatan 2017 - 2019 skripsi.

8. N. Sayekti, L. H. (2018). Analisis Risiko Depresi, Tingkat Sleep Hygiene Dan Penyakit Kronis Dengan Kejadian Insomnia Pada Lansia. Departemen Epidemiologi Fakultas Kesehatan Masyarakat Universitas Airlangga, April, 181-193.

9. Olvista, Andhyka, R., \& Suprihatiningsih, T. (2013). Sleep hygiene therapy. V(1), 61-67.

10. Rahmah, I. Z., Retnaningsih, D., \& Apriana, R. (2018). Hubungan Sleep Hygiene Dengan Kualitas Tidur Pada Lanjut Usia. Jurnal IImu dan Teknologi Kesehatan, $\quad 9(1)$. https://doi.org/10.33666/jitk.v9i1.58

11. Rohmawati, F. (2018). Hubungan Sleep Hygiene dan Kelelahan Fisik Dengan Pemenuhan Kebutuhan Tidur Lansia yang Bergadang di Pasar Agrobis Plaosan Babat Kabupaten Lamongan. In Journal of Chemical Information and Modeling (Vol. 53, Nomor 9).

12. Sarfriyanda, J., Karim, D., \& Dewi, A. P. (2015). Hubungan Antara Kualitas Tidur dan Kuantitas Tidur Dengan Prestasi Belajar Mhahasiswa. 2(2).

13. Sulistiyani, C. (2012). Beberapa Faktor Yang Berhubungan Dengan Kualitas Tidur Pada Mahasiswa. Kesehatan Masyarakat, 1(2), 280-292.

14. Suwarjana, i K. (2016). Statistik Kesehatan. Andi Offset.

15. Wahab, A. (2017). Hubungan Kualitas Tidur Dengan Migren Pada Mahasiswa Angkatan 2014 Fakultas Kedokteran Universitas Hasanudin. Fakultas Kedokteran Universitas Hasanudin, 168.

16. Wicaksono, D. W., Yusuf, A., \& Widyawati, ika yuni. (2019). Analisis Faktor Dominan Yang Berhubungan Dengan Kualitas Tidur Pada Mahasiswa Fakultas Keperawatan Universitas Airlangga. Fundamental and Management Nursing Journal, 1(1), 46. https://doi.org/10.20473/fmnj.v1i1.12131

17. Widhiyanti, T. K. ., Ariawati, N. ., \& Rustiyanti, N. . (2017). Pemberian Back Massage durasi 60 menit dan 30 menitmeningkatkan kualitas tidur pada mahasiswa ikip pgri bali semester genap tahun 2016/201. 11(1), 92-105. 11(1), 92-105. 